\section{AB0361 EFFECTIVENESS AND SAFETY OF INFLIXIMAB DOSE ESCALATION IN PATIENTS WITH REFRACTORY TAKAYASU ARTERITIS: A REAL-LIFE EXPERIENCE FROM A MONOCENTRIC COHORT}

A. Tomelleri ${ }^{1}$, C. Campochiaro ${ }^{1}$, S. Sartorelli ${ }^{1}$, F. Baldassi ${ }^{2}$, F. Fallanca ${ }^{2}$, M. Picchio' ${ }^{2}$, E. Baldissera ${ }^{1}$, L. Dagna ${ }^{1}{ }^{1}{ }^{1}$ IRCCS San Raffaele Hospital, Unit of Immunology, Rheumatology, Allergy and Rare diseases, Milan, Italy; ${ }^{2} I R C C S$ San Raffaele Hospital, Unit of Nuclear Medicine, Milan, Italy

Background: Most published evidence on infliximab (IFX) in Takayasu arteritis (TAK) refers to its use at the standard dose of $5 \mathrm{mg} / \mathrm{kg}$ every $6-8$ weeks ${ }^{1}$. However, in other diseases such as rheumatoid arthritis or Crohn's disease ${ }^{2,3}$, it has been already demonstrated that IFX often requires a dose escalation to maintain its response. Objectives: To evaluate effectiveness and safety of IFX dose escalation in TAK patients. To identify predictors of refractoriness to standard-dose IFX.

Methods: Medical records of IFX-treated TAK patients from a large single-centre observational cohort were reviewed. Decisions on IFX start, interruption, and dose modification were always made by the same experienced physician (EB). IFX therapy duration and reasons for dose escalation and therapy suspension were evaluated. Occurrence of adverse events was recorded. A comparison between patients who maintained IFX standard-dose and those who needed dose-escalation was performed. Factors predicting standard-dose refractoriness were analyzed.

Results: Forty-one patients were included ( 38 women; median age at IFX start, 36 [IQR, 28-45] years; median disease duration, 22 [13-60] months). Starting IFX dose was $5 \mathrm{mg} / \mathrm{kg}$ 6-weekly; 39 patients $(95 \%)$ were on concomitant csDMARD and 38 patients $(93 \%)$ on systemic glucocorticoids (GC). IFX dose escalation was performed in the majority of patients ( $n=28,68 \%$ ) (Figure 1). Persistence/ recurrence of clinical symptoms was the most frequent reason for dose escalation (62\%). Median IFX therapy duration was 39 (26-61) months in the standard-dose and 68 (38-87) months in the intensified-dose group. Patients in the intensified-dose group had a higher number of relapses (3.4 vs 0.8 events/patient) expression of a more aggressive disease phenotype. Nevertheless, in only 8 patients $(29 \%)$ from this group IFX was suspended, after a median of $38(31-71)$ months. Causes of suspension were loss of response $(n=7)$ or patient's request $(n=1)$. GC were successfully suspended in 4 patients from the standard-dose $(36 \%)$ and 3 patients from intensified-dose (11\%) group. Median daily prednisone dose was reduced from $10(6-10)$ to $3(0-5) \mathrm{mg}$ in the standard-dose group, and from $13(9-18)$ to 5 (4-5) $\mathrm{mg}$ in the intensified-dose group. Three patients from the intensified-dose group had a serious infection; one patient from the standard-dose group developed paradoxical psoriasis. At univariate analysis, younger age at diagnosis and at IFX start were associated with IFX escalation (Table 1).
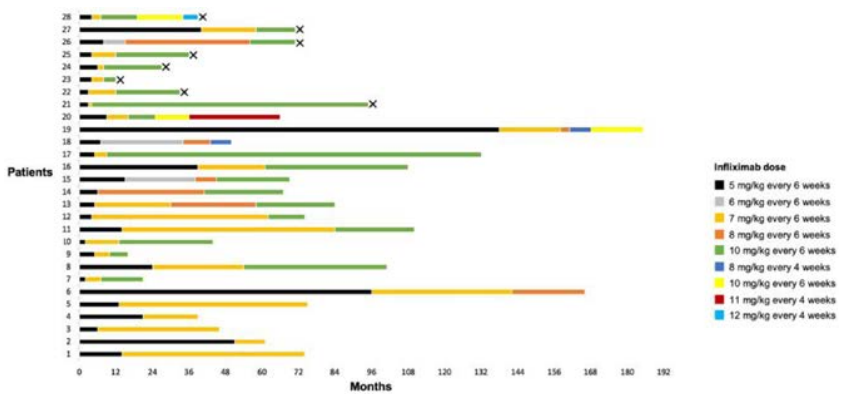

Figure 1. Infliximab dose escalation regimens (the cross $(\mathrm{x})$ indicates treatment suspension)

Table 1. Factors influencing IFX dose escalation in patients with TAK (Cox proportional hazards model)

\begin{tabular}{lccc}
\hline & Standard-dose IFX & Intensified-dose IFX & $P$-value \\
\hline Age at diagnosis, years & $40(34-46)$ & $30(23-40)$ & 0.031 \\
Diagnostic delay, months & $12(7-77)$ & $27(15-50)$ & 0.73 \\
Age at IFX start, years & $42(38-61)$ & $34(27-44)$ & $\mathbf{0 . 0 4 0}$ \\
Delay before IFX start, months & $33(14-90)$ & $24(11-53)$ & 0.48 \\
Daily PDN at IFX start, mg & $8.75(5-10)$ & $11.25(8.5-16.25)$ & 0.051 \\
CRP at IFX start, mg/L & $6.5(2.1-9.3)$ & $10.7(5.2-20.9)$ & 0.07 \\
Class V Numano, $\mathbf{n}(\%)$ & $3(30)$ & $16(57)$ & 0.133 \\
PETVAS score & $8(6-12)$ & $12(9-16)$ & 0.056 \\
\hline
\end{tabular}

Conclusion: In TAK, dose escalation can be a safe strategy to optimize IFX durability in refractory patients. Younger patients seem to be more refractory to standard dosages.

REFERENCES:

[1] Mekinian A, Néel A, Sibilia J, et al. Efficacy and tolerance of infliximab in refractory Takayasu arteritis: French multicentre study. Rheumatology. 2012; $51: 882-6$
[2] Ollendorf DA, Massarotti E, Birbara C, et al. Frequency, predictors, and economic impact of upward dose adjustment of infliximab in managed care patients with rheumatoid arthritis. J Manag Care Pharm. 2005;11(5):383-93

[3] Taxonera C, Olivares D, Mendoza JL, et al. Need for infliximab dose intensification in Crohn's disease and ulcerative colitis. World J Gastroenterol. 2014;20(27):9170-7

Disclosure of Interests: Alessandro Tomelleri: None declared, Corrado Campochiaro: None declared, Silvia Sartorelli: None declared, Francesco Baldassi: None declared, Federico Fallanca: None declared, Maria Picchio: None declared, Elena Baldissera Speakers bureau: Pfizer, Roche, Sanofi-Genzyme, Consultant of: Novartis, Lorenzo Dagna Consultant of: Abbvie, Amgen, Biogen, Bristol-Myers Squibb, Celltrion, Galapagos, GlaxoSmithKline, Novartis, Pfizer Roche, Sanofi-Genzyme, and SOBI., Grant/research support from: The Unit of Immunology, Rheumatology, Allergy and Rare Diseases (UnIRAR) received unresctricted research/educational grants from Abbvie, Bristol-Myers Squibb, Celgene, GlaxoSmithKline,Janssen, Merk Sharp \& Dohme, Mundipharma Pharmaceuticals, Novartis, Pfizer, Roche, Sanofi Genzyme, and SOBI DOI: 10.1136/annrheumdis-2021-eular.1537

\section{AB0362 DEMOGRAPHIC AND CLINICAL CHARACTERISTICS OF BEHCET'S DISSEASE PATIENTS}

S. San ${ }^{1}$, Ö. Özdemir Işık ${ }^{1}$, A. Yazici ${ }^{1}$, A. Cefle ${ }^{1}{ }^{1}$ Kocaeli Üniversitesi Tıp Fakültesi, Rheumatology, Kocaeli, Turkey

Background: Behcet's Disease (BD) is a systemic variable vessel vasculitis that involves the skin, mucosa, joints, eyes, arteries, veins, nervous system and the gastrointestinal system.

Objectives: In this study we aimed to present variety of involvements in patients who were followed up in our outpatient clinic with a diagnosis of BD.

Methods: Data of 394 patients diagnosed with BD between 2000-2020 were retrospectively reviewed clinical, demographic characteristics and systemic involvements.

Results: In our study $43.7 \%$ of BD patients were female, $56.3 \%$ were male and the mean age was $40 \pm 11$ years, disease average age of onset $36.5 \pm 10.6$, dis ease duration was $12.8 \pm 6.8$ years. It was observed mucocutaneus involvement $98 \%$ of the patients, uveitis in $35 \%$, retinal vasculitis in $2.8 \%$, arthritis in $24.9 \%$, arterial occlusion in $2.3 \%$, arterial aneurysm in $3.8 \%$, venous involvement in $19.8 \%$, gastrointestinal (GIS) involvement in $4.3 \%$, cardiac involvement in $1.5 \%$, and cranial involvement 7.1 (Table 1).

Table 1. The Data of Behçet Disease

\begin{tabular}{|c|c|}
\hline n (\%) & $\mathrm{n}=394$ \\
\hline \multicolumn{2}{|l|}{ Gender } \\
\hline Female & $172(43.7)$ \\
\hline Male & $222(56.3)$ \\
\hline Family History & $48(12.2)$ \\
\hline Fever \& Weight Loss & $21(5.3)$ \\
\hline Mucocutaneus involvement & $386(98)$ \\
\hline Oral Aphthous Ulcer & $379(96.2)$ \\
\hline Genital Ulcer & $256(65)$ \\
\hline Papulopustular lesions & 129 (32.7) \\
\hline Erythema Nodosum-like lesions & $150(38.1)$ \\
\hline Skin Pathergy Reaction & $185(47)$ \\
\hline Uveitis & $138(35)$ \\
\hline Retinal Vasculitis & $11(2.8)$ \\
\hline Venous involvement & $76(17.6)$ \\
\hline \multirow{2}{*}{ Thrombophlebitis } & $30(7.6)$ \\
\hline & $67(17)$ \\
\hline \multicolumn{2}{|l|}{ Deep venous thrombosis } \\
\hline Arthritis & $98(24.9)$ \\
\hline Monoarthritis & 74 (75.5) \\
\hline Oligoarthritis & $21(21.4)$ \\
\hline Sacroiliitis & $3(3.0)$ \\
\hline Artery Occlusion & $9(2.3)$ \\
\hline Arterial Aneurysm & $15(3.8)$ \\
\hline GIS involvement & $17(4.3)$ \\
\hline İleum & $9(2.3)$ \\
\hline Colon & $2(0.5)$ \\
\hline Rectum & $1(0.3)$ \\
\hline İleocolonic & $4(1)$ \\
\hline Cardiac involvement & $6(1.5)$ \\
\hline Pericarditis & $2(0.5)$ \\
\hline Ventricular thrombosis & $3(0.7)$ \\
\hline Atrial thrombosis & $1(0.2)$ \\
\hline Cranial involvement & $24(5.6)$ \\
\hline Parenchymal involvement & $13(4.6)$ \\
\hline Cerebral Venous Thrombosis & $11(2.8)$ \\
\hline Pulse steroid & $15(3.8)$ \\
\hline $1 \mathrm{mg} / \mathrm{kg}$ steroid & 48 (12.2) \\
\hline Infliximab & $13(3.3)$ \\
\hline Azathioprine & $184(46.7)$ \\
\hline Cyclophosphamide & $31(7.9)$ \\
\hline
\end{tabular}


When all patients evaluated in terms of renal findings, proteinuria was observed in 5 patients and hematuria was observed in 2 patients. 3 patients had proteinuria over than $500 \mathrm{mg} /$ day. Their renal biopsy findings; 2 of them were nonspecific involvements and one of them was minimal mesangioproliferative changes.

Conclusion: As a multi-system disease, general data have been presented, as clinical symptoms involve almost all systems of the body (1). REFERENCES:

[1] Behcet's disease Fereydoun Davatchi 1Int J Rheum Dis.2014 May;17(4):3557. doi: 10.1111/1756-185X.12378.

Disclosure of Interests: None declared

DOI: 10.1136/annrheumdis-2021-eular.1543

\section{$\mathrm{AB} 0363$ \\ PERIOPERATIVE MANAGEMENT WITH BIOLOGICS ON SEVERE AORTIC VALVE REGURGITATION CAUSED BY BEHÇET'S SYNDROME: THE EXPERIENCE FROM A SINGLE CENTER}

L. Sun ${ }^{1}$, J. Liu ${ }^{1}$, W. Zheng ${ }^{1} .{ }^{1}$ Peking Union Medical College Hospital, Chinese Academy of Medical Sciences and Peking Union Medical College, Department of Rheumatology and Clinical Immunology, Beijing, China

Background: Cardiovascular involvement in Behçet's syndrome (BS) is associated with poor prognosis and accounts for the leading cause of mortality and morbidity in $\mathrm{BS}^{1,2}$. Perioperative management of severe aortic valve regurgitation (AR) caused by $B S$ is critical while challenging. $A R$ caused by $B S$ is associated with a high incidence of severe postoperative complications, especially paravalvular leakage (PVL) due to the fragilities of aortic lesions and tissue inflammation, leading to a significantly increased risk of re-operation and life-threatening conditions ${ }^{3-5}$. For the perioperative management of patients with AR caused by BS, many patients respond inadequately to the combination therapies of glucocorticoids (GCs) and immunosuppressants. Meanwhile, rapid and efficient control of inflammation is critical in preserving cardiac function and surgical management. However, the application of biologics in the perioperative treatment of AR attributable to BS has not yet been evaluated.

Objectives: To investigate the efficacy and safety of biologics in the perioperative management of severe AR caused by BS.

Methods: We retrospectively analyzed twenty patients with severe AR caused by $\mathrm{BS}$ and were treated with biologics during the perioperative cardiac surgeries in our center between February 2016 and October 2020.

Results: Twenty patients with severe AR were enrolled, including 19 males and 1 female, with a mean age of $39.1 \pm 8.8$ years and median course 8 (IQR, $5.25-10$ ) years. Before biologics administration, $92.9 \%$ of the patients who underwent aortic valve replacement surgeries had failed conventional therapy and developed postoperative paravalvular leakage (PVL) at a median interval of 4 months. Biologics was administered during the perioperative period of 22 aortic valve surgeries, including preoperatively with a median interval of 3.5 (IQR, 2.75-4.25) months in 13 cases, or within three-month postoperatively in 9 cases, with background glucocorticoids (GCs) and immunosuppressants. After a median follow-up of 21 (IQR, 15-32) months, 11 out of 13 cases (84.6\%) preoperatively and 8 out of 9 cases (88.9\%) postoperatively treated with biologics were event-free. The BDCAF score improved significantly (7 vs. 0, median, $\mathrm{p}<0.0001)$. Significant decrease of ESR (25.0 (IQR, 11-36.25) $\mathrm{mm} / \mathrm{h}$ vs. 6.5 (IQR, 4-8.8) mm/h, p<0.001), and CRP (20.77 (IQR, 7.19-29.58) $\mathrm{mg} / \mathrm{L}$ vs. 1.53 (IQR, 0.94-2.92) $\mathrm{mg} / \mathrm{L}, \mathrm{p}=0.001$ ) were achieved rapidly and effectively. The dosage of GCs tapered from 40 (IQR, 30-60) mg/d to 10 (IQR, $5-11.25) \mathrm{mg} / \mathrm{d}, \mathrm{p}<0.0001$. Immunosuppressants were tapered in number and dosage in $6(30 \%)$ and 20 patients (100\%), respectively. No serious adverse event was observed.

Conclusion: Our study suggests that biologics was effective and well-tolerated for the perioperative management of severe and refractory AR caused by BS, which significantly reduced the occurrence of postoperative PVL and had a favorable GCs- and immunosuppressants- sparing effect.

REFERENCES:

[1] Saadoun D, Wechsler B, Desseaux K, et al. Mortality in Behcet's disease. Arthritis Rheum 2010; 62: 2806-2812.

[2] Thomas T, Chandan JS, Subramanian A, et al. Epidemiology, morbidity and mortality in Behcet's disease: a cohort study using The Health Improvement Network (THIN). Rheumatology (Oxford) 2020; 59: 2785-2795.

[3] Ando M, Kosakai Y, Okita Y, et al. Surgical treatment of Behcet's disease involving aortic regurgitation. Ann Thorac Surg 1999; 68: 2136-2140.

[4] Han JK, Kim HK, Kim YJ, et al. Behcet's disease as a frequently unrecognized cause of aortic regurgitation: suggestive and misleading echocardiography findings. J Am Soc Echocardiogr 2009; 22: 1269-1274.

[5] Guo X, Tian Z, Liu Y, et al. Preoperative immunosuppressive therapy reduces paravalvular leakage after aortic valve surgery in patients with aortic regurgitation attributable to Behcet's disease. Clin Exp Rheumatol 2016; 34: S26-S33.

Disclosure of Interests: None declared

DOI: 10.1136/annrheumdis-2021-eular.1568

\section{$\mathrm{AB} 0364$ \\ DO PATIENTS PARTICIPATING IN MEETINGS REPRESENT THE ACTUAL PATIENT POPULATION IN BEHÇET SYNDROME?}

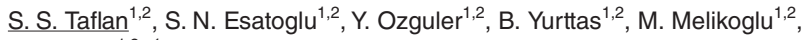
G. Hatemi ${ }^{1,2}$. ${ }^{1}$ /stanbul University-Cerrahpasa, Cerrahpasa Medical Faculty, Department of Internal Medicine, Division of Rheumatology, Istanbul, Turkey; ${ }^{2}$ Istanbul University-Cerrahpasa, Cerrahpasa Medical Faculty, Behcet Disease Center, Istanbul, Turkey

Background: The importance of patient involvement in healthcare research is increasingly emphasized. Patients participate as research partners in designing studies and development of management recommendations, measurement tools and outcome measures. However, ensuring representation of the genera patient population by specific patient groups may be challenging for multisystem diseases with heterogenous phenotype.

Objectives: We aimed to evaluate whether patients with Behcet syndrome (BS) participating in a patient convention represent the actual patient population attending the clinic.

Methods: A questionnaire was applied to 104 BS patients (Meeting group) attending the patient convention which was held during the Cerrahpasa Behcet Disease Symposium in Istanbul in February 2020. Patients had been invited to the convention through posters, advertisement on our website and social media. The questionnaire was conducted with a keypad given to the patients and it consisted of 21 items including age, gender, education level, working status, disease duration, BS manifestations, and treatment. The same questionnaire was filled by 97 consecutive patients (Clinic group) who attended our rheumatology outpatient clinic for their routine controls. Chi-square test was used to compare the groups.

Results: Table 1 shows demographic and disease characteristics of the patient groups. The groups were similar in terms of sex and education level. There were more men in both groups, probably reflecting the more severe disease course among men in BS. There were significantly more patients who were $>40$ years of age and had a disease duration more than 20 years in the Meeting group. Although there were more patients who had a job in Clinic group, the difference was not significant. Central nervous system involvement, vascular involvement, genital ulcers, erythema nodosum, and arthritis were significantly more common in patients in the Meeting group compared with those in the Clinic group. The frequency of eye involvement, gastrointestinal involvement and papulopustular lesions were similar in the two groups. Cyclophosphamide use was significantly more common in Meeting group compared to the Clinic group.

Table 1. Demographics, clinical characteristics, and treatments

\begin{tabular}{lccc}
\hline & $\begin{array}{c}\text { Meeting Group } \\
(\mathrm{n}=104) \\
(\mathrm{n} / \mathrm{N}, \%)\end{array}$ & $\begin{array}{c}\text { Clinic Group } \\
(\mathrm{n}=97) \\
(\mathrm{n}, \%)\end{array}$ & $P$ \\
\hline Oral aphthous ulcers & $88 / 97(91)$ & $94(97)$ & 0.13 \\
Genital ulcers & $86 / 104(83)$ & $68(70)$ & 0.045 \\
Erythema nodosum & $77 / 103(75)$ & $47(48)$ & 0.0003 \\
Papulopustular skin lesions & $69 / 103(67)$ & $75(77)$ & 0.09 \\
Arthritis & $78 / 102(77)$ & $46(47)$ & $<0.0001$ \\
Eye involvement & $51 / 103(50)$ & $53(55)$ & 0.48 \\
Vascular involvement & $42 / 98(43)$ & $25(26)$ & 0.036 \\
CNS involvement & $14 / 103(14)$ & $2(2)$ & 0.016 \\
Gl involvement & $14 / 97(14)$ & $6(6)$ & 0.10 \\
Prednisolone - still using & $30 / 104(29)$ & $34(35)$ & 0.37 \\
Prednisolone - ever used & $88 / 104(85)$ & $72(74)$ & 0.08 \\
Colchicine - still using & $43 / 100(43)$ & $46(47)$ & 0.57 \\
Colchicine - ever used & $86 / 100(86)$ & $74(76)$ & 0.10 \\
AZA - still using & $45 / 100(45)$ & $41(42)$ & 0.77 \\
AZA - ever used & $81 / 100(81)$ & $74(76)$ & 0.49 \\
CYC - still using & $1 / 96(1)$ & $0(0)$ & $\mathrm{NS}$ \\
CYC - ever used & $16 / 96(17)$ & $7(7)$ & 0.048 \\
bDMARDs - still using & $20 / 101(20)$ & $26(27)$ & 0.31 \\
bDMARDs - ever used & $28 / 101(28)$ & $32(33)$ & 0.44 \\
\hline
\end{tabular}

* Adjusted $P$-values by Bonferroni correction were <0.001.BS: Behcet Syndrome, CNS: Central nervous system, GI: Gastrointestinal, AZA: Azathioprine, CYC: Cyclophosphamide; bDMARDs: Biologic disease-modifying anti-rheumatic drugs; NS: non-significant

Conclusion: Patients in the Meeting group had more severe disease compared to the Clinic group. Patients with all types of involvement were adequately represented in the Meeting group.

Disclosure of Interests: None declared

DOI: 10.1136/annrheumdis-2021-eular.1643 